\title{
A MAGICAL REORIENTATION OF THE MODERN: Professional Organizers and Thingly Care in Contemporary North America
}

\author{
KATIE KILROY-MARAC \\ University of Toronto Scarborough \\ (iD http: / / orcid.org/0000-0003-1673-217X
}

Fran is a quick-witted and energetic woman of about fifty who recently launched her own professional home-organizing business in Toronto. ${ }^{1}$ One morning, as we sat drinking coffee together, she told me about a regular client of hers - a woman she'd just seen again earlier that week. The woman was far from rich, Fran said, “but she's got, rough guess, four hundred pairs of summer shoes and more clothes than she could ever wear, not to mention loads of other stuff. The first time I walked into her place, I felt like was going to hyperventilate. ... There was absolutely no sound in there because it was so full of stuff. You know, it was like walking into a cathedral, or a womb-I think, to her, that's what it was."

Professional Organizers (POs) like Fran are keen observers of how people relate to and manage their material possessions. Many express an almost anthropological desire to understand their clients' attachments to things and, more broadly, to reflect on the stuff of contemporary North American life. It's not just the extreme cases of acquisition, accumulation, or excess that POs find interesting or worthy of discussion, but also the mundane, ordinary things that settle into our daily lives - the paper clutter (receipts, tax documents, letters, junk mail), the plastic goods, the useless kitchen gadgets, the kids' artwork, the new-butsoon-to-be-obsolete electronic devices, and the things we inherit when a parent or loved one dies. 
A seemingly simple question had led me to seek out and talk to POs in Toronto: how, in North America and at this particular historical moment, are we to manage and be with our ever-expanding world of material things? Already I had come across a strong prescription about how not to be: according to the newly defined Hoarding Disorder diagnosis in the fifth edition of the Diagnostic and Statistical Manual of Mental Disorders (DSM-V; American Psychiatric Association 2013), pathological hoarding has as much to do with the improper management and organization of objects as it does with excessive accumulation. Here consumption remains a late capitalist raison d'être, but it must, above all, be properly managed. One must not only know what to keep and what to discard, but how to arrange and store objects in their proper place.

By way of a close engagement with the DSM-V, popular home and lifestyle magazines like Real Simple, and the burgeoning occupation of professional organizing, this article attends to things in excess and in disarray, and looks critically at how order is made out of disorder in discourses about stuff in contemporary North America. Drawing on insights offered by the anthropologist Mary Douglas (1966) in Purity and Danger, I take as a point of departure the idea that disorder is a far from natural or absolute category. Rather, the practice of naming disorder and making order is both instrumental and highly symbolic; it serves to distinguish social and moral categories and draw boundaries between different kinds of people, not just through an appeal to hygiene, health, or self-improvement but also through the production of specific structures of feeling and affect — fear, disgust, vigilance, revulsion, pity, and self-righteousness - that in turn serve to maintain these distinctions. Discourses of order and disorder, I suggest, carry within them strong judgments about virtue, affluence, and class (Bourdieu 1977, 1984).

My investigation begins with a discussion of how certain forms of material disorder have, in the North American popular and psychiatric imagination, come to stand alternately as evidence, symptom, or potential cause of mental disorder. Showing how the logic of late capitalism is both reflected and enforced through cultural idioms of mental health and illness (Cvetkovich 2012; Kleinman 1988; Littlewood 2002; Martin 2007), I unpack the various regimes of order that underpin these discussions to reveal a specific set of directives about what constitutes appropriate object management and thingly care in contemporary North America. I then turn my attention to the question of ordering as both a practice and a process, continuously undertaken and again undone, never fully complete (Law 1994). Drawing on interviews and fieldwork encounters with twenty-one POs in Toronto and throughout southern Ontario, I describe how they aim to reorient 
their clients materially, morally, and affectively by reordering their habits and things. ${ }^{3}$ In theory, POs endeavor to bring people's overpowering relationships with their material possessions into line with a specific regime of caring for, with, and about things that is predicated on an absolute distinction between subject and object. In practice, however, many POs find themselves immersed in a reality that is more vibrant-materialist than it is Cartesian. The organizers fully recognize the complex ways that people become attached to, intermingled with, and even dispersed in things, and their work requires them to regularly plunge into and manipulate this world of "vibrant matter" (Bennett 2010). Here, I suggest, POs emerge as a new species of healer whose interventions endeavor to excise objects from subjects and vice versa, and who by extension seek to transform dividuals into individuals (LiPuma 1998). ${ }^{4}$ From this angle, POs and their interventions appear to be resolutely disenchanting. And yet, a paradoxical double movement also animates their work. For just as POs act to disrupt the "secret sympathy" (Frazer 1906, 53) their clients share with their material things, they nevertheless operate within a realm of magical correspondence where matter and mind are imagined to reflect and affect one another, and where bringing order to a client's possessions means also bringing order to his or her mind.

\section{A WORD ABOUT ANTHROPOLOGY'S THINGS}

To investigate regimes of material order and disorder is also to probe objects and things. ${ }^{5}$ The idea that material objects are "closely tied to humans and their ways of knowing" (Hodder 2012, 14) is certainly not new to sociocultural anthropology - the social significance of objects has been central to the discipline's own history and development. Since the 1980s, studies of material culture in anthropology have examined the "social lives" or biographies of things (Appadurai 1986; Kopytoff 1986), as well as the way subject and object may come to coconstruct one another (Miller 1987; Tilley 1999). ${ }^{6}$ Others have gone even further to challenge the distinction between subjects and objects. Through the lens of Actor Network Theory (ANT), things - and especially human-created technologies - are scrutinized for their capacity to enable or restrict human action, sociality, and even ethical behavior while nevertheless fading into the apparently neutral infrastructure of our everyday experience (e.g., Latour 1987, 1992; Law 1992). ${ }^{7}$

Even more recently, the new materialist movement has built on and extended the work of ANT to approach things in their "vibrant" materiality (Bennett 2010; see also Ingold 2011 on the "vitality of materials") and as having an agentive 
force (Knappett and Malafouris 2008) all their own. ${ }^{8}$ Critiquing the ontological division and privileging of subject over object, humans over nature, and living things over nonliving things, this movement is as much a political project as it is a philosophical one, for it insists that "disregarding materiality and material capacity for agency leaves humanity enduring its own myth of exceptionalism, with the political costs of the continued purveyance of economic, gendered, racial, and further ideational inequalities" (Poe 2011, 154; see also Coole and Frost 2010; Haraway 2003).

Though I myself am less swayed by the call to attribute agency to things than I am by the idea that personhood (Strathern 1988) and even human agency (Gell 1998) may be dispersed into or extended through things, I am nevertheless fascinated by what Jane Bennett (2004, 349)_ building on the work of Gilles Deleuze, Baruch Spinoza, and Henry David Thoreau, among others - has referred to as "thing-power" materialism, an approach that "figures materiality as a protean flow of matter-energy" and "emphasizes those occasions in ordinary life when the us and the it slipslide into each other." While the tension between Strathern's distributed personhood and Bennett's (2010, 31-32) theory of “distributive agency" - which "does not posit a subject as the root cause of an effect" but instead "points to a swarm of vitalities at play" - may be unresolvable, it is nevertheless productive, and I endeavor to hold them in the same frame here. It is the slipsliding of the us and the it, as well as the enduring attachments that may grow out of such encounters and the way people may see themselves in or as their stuff, that sits at the center of my inquiry, as well as of the interventions of POs that aim to detach people from their things. I turn to the techniques used by POs later in this article. First, however, I consider dominant North American cultural discourses about the appropriate (and inappropriate) ordering and accumulation of everyday things, looking specifically at how ideas about mental health and illness are grafted onto or derived from these discussions about our daily practices with stuff.

\section{MATERIAL DISORDER AS EVIDENCE OF MENTAL DISORDER}

Within early psychoanalytic discourse, hoarding behavior was linked to the notion of the "anal character" (Abraham 1997; see also Freud 1959; Jones 1950) and described as a "regression to a childlike state (as is the fascination with excrement) or an attempt to stop time or bring up the past” (Lovell 2007, 326). Folded into the earlier versions of the DSM, hoarding behavior stood as a sign or symptom of mental illnesses like Obsessive Compulsive Disorder, dementia, and 
schizophrenia; in the revised DSM-IV, compulsive hoarding was listed as a diagnostic criterion for Obsessive Compulsive Personality Disorder (Mataix-Cols et al. 2010). It was with the 2013 release of the DSM-V that Hoarding Disorder (HD) took its place as a disorder in its own right. And yet, looking more closely, we see that HD doesn't really stand alone at all: an estimated 75 percent of individuals diagnosed with HD are said to have a comorbid mood or anxiety disorder (Frost, Steketee, and Tolin 2011), and hoarding behavior is still listed as symptom of numerous other disorders.

The question of how and in what instances HD (as disorder) can be disambiguated from hoarding behavior (as symptom) plays an important role in my larger research project, as does the question of why both popular and professional conversations about hoarding — not just as mental illness but also as public health hazard and as media spectacle- have emerged with such vigor in North America during the past fifteen years, amounting to what Susan Lepselter $(2011,920)$ has termed a "collective fetish for the hoarder's fetishes." Hoarding, we are told, affects between 2 and 5 percent of the population (Mataix-Cols et al. 2010); according to these sources, the myriad physical and psychological dangers of the condition should not be underestimated (Steketee and Frost 2003). The urgency and ubiquity of this crisis are constantly reaffirmed by popular hoarding TV shows, as well as by regular news reports of hoarding-related fires and deaths.

The evolution of HD as a veritable psychiatric diagnosis is a curious thing, as is the DSM-V itself. From the negative space of the manual, a kind of ideal personality emerges that appears to be universal and unmarked, but is, of course, culturally and historically situated. Particularly interesting about HD is that because it hinges on stuff, it serves to distinguish supposedly normal late capitalist practices of accumulation, organization, and divestment from pathologized forms of being-with-things. The disorder bears the mark of what Ian Hacking (1998) has described as a "transient mental illness," meaning not a disorder that comes and goes within a single person, but rather one that appears suddenly — and sometimes quite dramatically_within an "ecological niche" (Hacking 1998, 13) of a given culture and location, has its moment, and then may just as readily recede. This is not to say that transient mental illnesses like HD are caused or created by, say, late capitalist consumer culture (and the social relations it encourages or inhibits), or by a neoliberal restructuring of subjectivities, or that such disorders are the confabulation of overeager psychiatrists or pharmaceutical companies, or that they are the product of media sensationalism, though all of these elements and many more have played a part in the making (and the making recognizable) 
of HD. It is also not to say that people in hoarding situations and their families do not endure suffering, alienation, and distress, for many certainly do. ${ }^{9}$ However-and this is an important point-hoarders tend not to identify excessive accumulation and/or material disorder as the primary source of their suffering. In psychological terms, the hoarding behavior at the heart of HD is described as being more or less egosyntonic (that is, generally acceptable to-and in line with - one's self-image). In practical terms, this means that for many people who hoard, it's not the stuff itself, but the threatened or actual removal of stuff and the discarding of things that causes the most distress (Gibson et al. 2010). In other words, the intervention is often experienced as distressing, while the things are not; hoarders have to be convinced that their stuff is the true cause of their suffering.

An example of the extreme anguish and dread felt by hoarders when faced with the idea of parting with their stuff _ even apparently nonsentimental items like junk mail and magazines - is illustrated in Debra's story, recounted by Randy Frost and Gail Steketee (2010) in their book Stuff: Compulsive Hoarding and the Meaning of Things. Debra describes her things as "fragments" or "extensions" of herself, explaining: "Whatever comes into my life has come for a purpose. I'm supposed to have it. It's a part of me-an extension of me" (Frost and Steketee 2010, 116). She goes on to speak of the anxiety she feels about being separated from her stuff in more relational terms: "It's like asking me to throw out my children. They'll be dead. I'll kill to prevent that” (Frost and Steketee 2010, 116). Debra also expresses a profound desire to hold on to and "contain" any item with which she comes into contact: "Picture a cartoon with thought bubbles. I have a hundred million bubbles. Junk mail is one of them. If I throw it away, it's out there without me, out of containment. I want a bubble around me and all my stuff to keep it safe" (Frost and Steketee 2010, 113). Contact with things, for Debra, is always a slip-sliding - things become part of her and she, in turn, is (re)constituted by (and also extended and dispersed in) these parts. The mere thought of being separated from her things, akin to losing a part of herself or losing her own children, causes Debra overwhelming distress.

A final noteworthy feature of the HD diagnosis is that one simply cannot imagine the diagnosis being assigned without some evidence of material disorder coming first - HD is simply not verifiable as a psychiatric condition in the absence of the stuff. This material proof — whether by way of photographs, documentation from city agencies or service providers, or a home visit — must necessarily precede the diagnosis (Mataix-Cols 2014). Extreme material disorder thus appears to stand 
as evidence, physical projection, and mimetic expression of the mental disorder that is its cause. Disorder is the disorder, in a very real sense.

\section{MATERIAL DISORDER AS A SYMPTOM OF MENTAL DISORDER}

The same period that saw the emergence of HD as a mental illness gave rise to other strong reactions to excessive accumulation and material disorder as well, including the birth of a booming clutter-management industry and a multitude of consumption-critical and so-called simple-life movements. Within the former, and specifically within the domain of professional organizing, a condition known as chronic disorganization (CD) was first described by the renowned PO Judith Kolberg during the 1990s. The term (and its cognate, "challenging disorganization,” which in 2011 was "selected to replace 'chronic disorganization' because it was seen as less clinical sounding, less confusing, more inclusive and more hopeful"; see http://www.challengingdisorganization.org/content/resourcesoverview) enjoys great currency with POs throughout North America. In the United States, organizations like the Board of Certification for Professional Organizers and the Institute for Challenging Disorganization have begun to train and accredit POs and aim to standardize the field worldwide; titles include CPO (Certified Professional Organizer) or CPO-CD (Certified Professional Organizer specializing in Chronic Disorganization). The profession remains to a large extent unregulated, however. In Toronto, some POs are long established and accredited in their field, others have learned through mentorship, and still others begin without much prior experience at all, taking an entrepreneurial risk in opening their own PO company.

I must emphasize, as POs always do, that chronic disorganization is not a medical or a psychiatric diagnosis. Rather, POs describe CD as a behavior set or an orientation toward stuff that makes it difficult for those who experience its symptoms to keep their material possessions in order. While CD is not itself a medical condition, POs note that it does sometimes arise from-and, in fact, stands as a symptom of - other mental or physical health problems. Barbara, a certified CPO-CD who has been working as a professional organizer in southern Ontario for nearly fifteen years, explained to me that most of the clients she works with "have some kind of impairment of their executive functioning abilities. I have clients with ADD; I have clients who have suffered brain injuries. Their brains just don't work in an organized way, and they need a lot of help with what lots of people take for granted." Describing her client base, Ellen, also a CPOCD, told me that she has "very few clients who haven't been diagnosed with 
depression.” Denise, another CPO-CD in Toronto, told me that most of her clients suffer from depression, fibromyalgia, or other physical challenges. Some of their clients have sought treatment for their condition, and a few take medications, but many others are self-diagnosed. According to Barbara, clients with CD tend to have struggled with stuff their whole lives; many of her clients have tried to "get organized" on their own many times over, but with great difficulty and often to no avail. For others, the POs explain, CD may stem from a life event, sometimes traumatic, that led to a period of "situational disorganization" that was never resolved. Professional organizers often describe chronic disorganization as a spectrum, where hoarding is imagined as an extreme version of CD that occupies a place on the spectrum's far end. But, POs say, hoarders and persons with CD are easy to distinguish from one another. A Toronto PO named Corine explained to me that, in contrast to hoarders, persons with CD tend to be distressed by the state of their living spaces; they have a certain degree of insight into their situation, and they recognize that the accumulation and disorder of stuff in their lives is detrimental to their well-being. Unlike hoarding, chronic disorganization could be described as egodystonic, or in conflict with the needs and goals of the ego. People with CD want to change their habits and behaviors around stuff, but they often don't know how to do it on their own. They are much more likely to enlist the help of a PO; they welcome intervention.

\section{MATERIAL DISORDER AS A CAUSE OF MENTAL DISORDER: Pursuing the Aesthetic of the Simple}

The latest edition of Real Simple magazine was waiting for me in my mailbox when I got home last night. Now, I tell myself that my interest in this magazine is purely research-related - after all, I approach it primarily as an ethnographic object. And yet this magazine is so enticing, so hard to resist. Here is a house full of clean surfaces, ingenious storage systems, and closets that don't spill out at your feet when you open their doors. And because of this beautiful, functional, and clutter-free domestic order, the people depicted within the magazine clearly have more free time, more meaningful relationships, less anxiety, better general health - they have achieved a more highly evolved sense of well-being. As I leaf through the pages, I am assured that by implementing even a few of its organizing tips I will feel better, be better. The catch, of course, is that the real portrayed in this magazine is an intricately manufactured and carefully produced image, and the aesthetic of the simple itself takes a huge investment of time, energy, and even (despite the emphasis on frugality and saving that runs throughout the mag- 
azine) money. Here, simple is highly cultivated; it emerges as the product of ongoing vigilance and the relentless labor of ordering. It is also an undeniable marker of class status.

In an interesting twist on Thorstein Veblen's (1899) conspicuous consumption, what is most conspicuous and-given the centrality of consumption in daily North American life and the fact that "clutter . . . is an almost inevitable feature of consumption" (Cwerner and Metcalfe 2003, 236)—most remarkable about these well-ordered domestic spaces isn't the careful staging of luxury items, but rather all the things that aren't there. It's not just the meticulous arrangement of these interiors, then, but the obvious absence of clutter that signals a new form of affluence. We imagine that the inhabitants of these domestic spaces have precious time, energy, and money to devote to ordering; they are able to keep on top of the in-and-out flow of objects, mail, garbage, toys. Or perhaps they hire someone else to do it for them. In any case, a close look at the not-there renders visible the practices of organizing and divestment that often contain within themselves their own practices of consumption. One need only call to mind the cluttermanagement industry that has emerged over the past several years - from POs to cleanout services and self-storage companies that will bring your storage pod right to your front door. Or think about retail chains like the Container Store, which sell objects whose sole purpose it is to hold, carry, or keep other objects (shoes, laundry, wrapping paper, thumbtacks) in their place.

As the visible absence of clutter signals affluence, it may also signal virtue; the two are, in fact, closely intertwined. In the pages of home and lifestyle magazines like Real Simple and in larger public conversations about consumption these days, there exists a strong moralizing discourse about the merits of moderation, self-regulation, and self-discipline amid endless possibilities for acquisition and accumulation. In this there are many parallels with public conversations about obesity in North America that have emerged with the progressive medicalization of weight during the past twenty-five years (Campos et al. 2006; Greenhalgh 2012). As with talk about thinness versus fatness, talk about the proper and improper accumulation of stuff plays into a "virtue discourse" (Halse 2009); those who consume too much or cannot manage their object worlds are seen as being out of control, lazy, and undisciplined. Several POs I interviewed made explicit connections between material accumulation and excess weight, on the one hand, and material order and weight management, on the other. Allie, a young PO who has been working in the Toronto area for about four years, described it like this: "Stuff tends to weigh you down. If you have a lot of stuff around you, you 
feel heavier. As you let things go, you feel lighter. There have even been studies showing how, when people let go of stuff, they are actually able to lose weight. Holding on to stuff and not letting go of it, it weighs on people and holds them back." The increasing tendency to medicalize material disorder by framing it as either a physical projection, symptom, or cause of mental illness does not dissolve the virtue discourse around stuff, but rather builds on the moral model in new ways, as do discourses surrounding the current so-called obesity epidemic in the United States (Greenhalgh 2012; see also Boero 2007).

The idea that certain forms of material order - especially those that can be brought into line with this aesthetic of the simple - can engender happiness and well-being plays into what Laurence Kirmayer (2002, 316) has described as a larger "global monoculture of happiness in which we are all enjoined to work to achieve the good life, which is understood to reside in being pain-free [and] completely comfortable." However, while Kirmayer (2002, 316) also described the "good life" as being "ready and able to acquire and consume the greatest quantity and variety of the newest goods and fashions," the new aesthetic of the simple depicts this good life not in terms of one's ability to accumulate but to resist - and even reject - accumulation and keep order. The central idea here has a double valence: just as simplicity and order can bring happiness, material excess or disorder can cause mental or emotional distress (Cwerner and Metcalfe 2003). This is a core belief shared by numerous consumption-critical lifestyle movements in North America and Europe. These include the Minimalist movement, a U.S.based group that espouses a radical downsizing of one's possessions as the key to a saner, more rewarding life (see Millburn and Nicodemus 2011) and the Tiny House movement, which over the past ten years or so has advocated simple living in architecturally innovative small-scale homes (generally under five hundred square feet). Movements like these mark a shift to what journalists and consumer reporters have noted as a turn to "inconspicuous consumption" among the affluent; that is, a turn toward spending money on experiences, services, and personal enrichment rather than material goods. Consumption is still central to the good life, then, but it is a particular form of consumption that is weary of accumulation, critical of disorder, and most visible in the conspicuous display of what is not there.

\section{PROFESSIONAL ORGANIZERS AS HEALERS}

Barbara told me that when she began organizing some fifteen years ago, "there was this idea that organizing was something you do to your clients. You 
went to their house, you organized their stuff, and then you left." Things have changed a lot since then, she explained. Professional organizers described their work to me as coaching, acting as a sounding board, lending focus, setting goals, teaching, transferring skills, modeling behavior, acting as a mirror, and helping clients establish new habits. Several POs also noted that their work resembled therapy, though it appears that the more formal accreditation a PO has, the more reluctant that $\mathrm{PO}$ is to think of professional organizing in those terms.

Professional organizers work with people on all points of the "clutter spectrum." Sometimes they assist with simple projects that take only a few daysredesigning a home office or flipping seasonal gear — or they help clients downsize for a move. For POs who work with chronically disorganized clients and those who hoard, however, the visits may stretch over a period of months or even years. In these cases, POs get to know their clients very well, and their relationships can become intensely personal. Over time, their clients open up to themthey reveal their disappointments and dreams, their dysfunctional relationships, past traumas, wishes, and fears - and these conversations often bubble up around the things that the PO and client sort through together. These things, some of which have not been actively handled or manipulated for years, stand not just as souvenirs or aides-mémoire, but as repositories of deeper memories and expectations that may trigger, like Marcel Proust's madeleine, a rush of past experiences, images, and feelings. "All these things that have been held onto- these are the material remains of a person's life," a PO named Jean explained to me. And even beyond linking a person to his or her past or being imagined as constitutive fragments of memory or identity, there is the undeniable physicality of the stuff itself. "They really are connected to their things - they are part of them," Jean told me. "It can get intense. I have to listen attentively and be responsive, but I also have to keep gently bringing my clients back to the present, back to their goals. It isn't easy. You can get pretty deep."

What kinds of things are POs brought in to sort and organize? Across the board POs talked about the ubiquity of paper clutter that overwhelms their clients' lives. For Fran's clients, whom she describes as financially comfortable and not "full-blown" hoarders, the big things are clothes, host gifts, and items purchased to be gifted but that somehow "stuck" and never made it out of the house. Fran notes that many of these items remain unused, and many still have their original price tags. Barbara and Ellen, whose clients often exhibit CD or hoarding behavior, point to newspapers, magazines, pamphlets and leaflets, rescued objects, food wrappers, used bottles, and things that are beyond repair. While some of 
their clients' things_ - photos, journals, souvenirs, and mementos — do have obvious sentimental value, POs explain, most do not, and yet their clients are attached to their things in powerful ways.

I now turn to describe two techniques used by POs to intervene in the complex affective attachments their clients have with their things. Interestingly, these techniques seem to work in opposite directions but toward the similar end goal of "letting go." This key phrase and aspiration in the world of professional organizing (as well as in self-help literature, life coaching, and healthy-lifestyle movements) carries multiple meanings and is construed as a central component of decluttering, as well as of relieving distress and achieving well-being. The first technique, which was described to me in detail by Denise and reiterated by several other POs, is one that involves blocking the "tactile sympathy" that clients have for their possessions. "Sometimes we don't like clients to touch their stuff," Denise told me. "If I'm trying to get a client to decide on whether or not we're going to keep this mug," said Denise, gesturing toward and then picking up a yellow, herbal tea-filled mug that sat between us on a café table one afternoon, "well, if they touch this mug, they're going to keep it. So very subtly, if I can hold the object, and let them look at it, and let them talk through what they think and feel about it without letting them touch it, that's one of the strategies that can be very useful in working with some clients." By putting physical space between clients and their stuff and disallowing touch, POs attempt to shift them away from a tactile, sensuous mode of being with things and into a visual mode, thereby imposing a supposedly appropriate distance between subject and object that will ostensibly loosen their clients' attachments to and identification with the things in question. From Denise's perspective, this distance allows for a rational assessment of the mug; it allows the owner to "see" the mug's key attributes more clearly and act toward it in a more intentional way, thus choosing to "let go" of the mug (which generally means giving it away, donating it, or throwing it out), to keep the mug for daily use (as one of a chosen few that will be kept in circulation), to display the mug (which means that it will be selected for its special attributes or value that set it apart from the rest), or to store the mug away.

The second method used by POs works in a seemingly opposite direction but toward the same key objective of letting go. Here, POs encourage clients to think with and as their thing; they ask their clients to consider the situation from the thing's point of view. Hoarders and people with CD tend to personify things, acting as if they have "a life and a soul," explained Ellen. "So one of the strategies we use . . . is to go with [it]. What the heck! Why not? If it will help the 
individual stay better organized, then use it!" Jean told me a very similar story and walked me through how she presents this to her clients:

I say, OK. This toy that belonged to your son, who's now forty-five and doesn't have kids of his own: What does this toy want? Where would it be happiest, most fulfilled? Is it happy at the bottom of a pile, not being used, collecting dust? I don't think it is. Let's figure out where it could be happy, where it could have a life, and let's get it there. Sometimes this does the trick. They want their possessions to be happy, too. ${ }^{10}$

In each of these techniques, POs attempt to intervene in the close affective relationships their clients have with their things and may even physically insert themselves between client and object. In their effort to loosen these deep attachments, however, Jean and the other POs must first arouse and evoke them. Much more than simply referencing the "social life" or "biography" of an object to separate these from their clients' own (Appadurai 1986; Kopytoff 1986), POs' interventions suggest that the boundaries and distinctions between subjects and objects are not so natural after all — that we are always already part of our things and our things part of us, and that these connections are not the exception but the rule. Professional organizers necessarily recognize this world of powerful attachments, where persons are embedded in things and things are extensions of people; they dive into and attempt to hold at bay this world constituted by a vital materiality in which "non-human others (whether stones, trees, or human produce; axes, knives, mobile phones, coffee mugs and the air surrounding them all)" may "take on appearances quite different from that of the human, [but] are [nevertheless] understood to be of the same essence, animation and intentionality - that is, they are alive" (Clarke and Mcphie 2014, 9). Many POs themselves thus take on something of a vibrant-materialist perspective, which proceeds not from the idea that their clients "have lost the ability to distinguish between person and thing," but instead that they "have an exceptional [and perhaps too acute] awareness of the extent to which all bodies can intertwine, infuse, ally, undermine, and compete with those in its vicinity" (Bennett 2012, 256). In this immanent materiality, boundaries between subjects and objects are always artificial and must be externally imposed, and it is the work of the POs to help perform the task. ${ }^{11}$ 


\section{CONCLUSION: In the Realm of Magical Correspondences}

Professional organizers, armed as they are with the language of self-improvement and well-being, are sometimes described as "enforcers of order" (Denegri-Knott and Parsons 2014, 89), scornful of - and hell-bent on correctingtheir clients' apparently "irrational” object relations. My ongoing involvement with POs, however, has revealed an orientation much more akin to that of a healer who acknowledges the slip-slidiness of people and things, and who intervenes in this domain - and in those private domestic spaces that, as Fran observed, are like cathedrals and wombs - to establish a different kind of order that they take to be neither natural nor pregiven. Professional organizers work to insert distance between clients and their material possessions by dissolving or rerouting attachments, and where personhood has been distributed or extended into things, POs work toward excision and extraction. As erectors of boundaries, POs, we might say, endeavor to transform dividuals - heteronomous, dispersed actors for whom personhood is primarily constituted in and through relationships with things and people external to the self-into individuals, persons who are autonomous subjects in relation to external objects and who thus appear to be self-contained, singular, whole, and complete-in-themselves (LiPuma 1998).

But if the work of POs appears to be a disenchantment of sorts, there is also a re-enchantment. In a brilliant recent article about storage practices in the United States, Sasha Newell $(2014,187)$ has suggested that a close look at these "practices reveals . . . a magical mode of thinking that typically goes unnoticed in public life." So too, I argue, does the work of professional organizers. At the same time that POs attempt to sever connections between people and things, they also hold tight to another form of magical correspondence based on the belief that mind and matter may mirror, project, and affect one another - that a cluttered house might stand as evidence for (or result in) a disordered mind, and conversely, that a disordered mind may lead to a cluttered house. Operating according what James Frazer (1906, 52) dubbed as homeopathic or imitative magic and the principle that "like produces like," POs adhere to a pervasive cultural logic, described earlier, that reads material disorder as evidence, symptom, or potential cause of mental disorder. It is this very logic that animates the work they do. As POs manipulate the objects and boundaries of their clients, they aim to reorient them not just materially but also emotionally, morally, and affectively. Because they hold as true the existence of a profound connection between the relative order or disorder of a person's domestic space and his or her state of mental health and well-being, the sorting and reordering work they 
do with their clients' possessions is imagined to have a similar effect on their clients' minds. From this perspective, POs themselves operate according to the principle of mimetic sympathy and the belief that "like acts upon like, and in particular, cures like" (Mauss 1972, 68).

My ongoing fieldwork among POs has thus led me to understand them less as enforcers of a rational, disenchanted order of object management, or even as "witchfinders, [who] systematically . . . overturn . . . the contents of a home to reveal its irrational interiority" (Newell 2014, 203), than as agents of a kind of magical reorientation of the modern. For as POs aim to bring their clients' relationships with stuff into line with an order predicated on a controlled passion for objects and the maintenance of an appropriate distance between people and their things, they also offer their clients a magical promise: that ordering their material possessions according to these premises will bring about an ordered mind, and by extension, a happier and more fulfilled life. It appears, then, that POs intervene into one kind of "secret sympathy" to manipulate another. The work they do with their clients illuminates the magical correspondences between objects and people, matter and mind, that are alive and well in the contemporary North American popular and psychiatric imagination.

\section{ABSTRACT}

Within the past decade, material disorder - especially that of the domestic varietyhas come to stand alternately as evidence, symptom, and potential cause of mental disorder in the North American popular and psychiatric imagination. Sources ranging from the newly defined Hoarding Disorder diagnosis in the DSM-V, to popular media, to agents of the burgeoning clutter-management industry describe disorder in terms of an irrational attachment, closeness, or overidentification with objects. At the same time, these sources imagine order to result from the cool distance and controlled passion a person is able to maintain toward his or her possessions. Drawing on more than twenty interviews and numerous fieldwork encounters with professional organizers (POs) in Toronto between 2014 and 2015, this article describes how POs aim to reorient their clients materially, morally, and affectively to relieve the disorder they report in their lives. Here, I argue, POs emerge as a species of late capitalist healer whose interventions are animated by a paradoxical double movement. For just as POs act to loosen the object attachments and disrupt the "secret sympathy" their clients share with their possessions, they operate within a realm of magical correspondence where matter and mind are imagined to reflect and affect one another, and where bringing order to a client's possessions means also bringing order to his or her mind. [material culture; domestic order; disorder; mental health; late capitalism; new materialism; North America] 


\section{NOTES}

Acknowledgments This research is funded by a Connaught New Researcher Award from the University of Toronto. A heartfelt thanks to Kristen Drybread, Sarah Hillewaert, Amira Mittermaier, and Jenny Sime for their helpful comments on earlier drafts of the manuscript. Audiences at McMaster University and the University of Toronto Scarborough also provided critical feedback. Finally, I am grateful to editors Dominic Boyer, James Faubion, and Cymene Howe, as well as Cultural Anthropology's anonymous reviewers, for their constructive suggestions and encouragement.

1. In many ways, Fran fits the typical profile of a professional organizer working in the United States or Canada today. The vast majority of those affiliated with the National Association of Professional Organizers, based in the United States, and Professional Organizers of Canada, which boast upward of four thousand and five hundred members, respectively, are Anglo/white middle-class women between the ages of forty and fiftyfive.

2. Fran also noted - about the space, the silence, and her work with the client - that "it was very relaxing, actually, once I got used to it, because it was so quiet."

3. Initial interviews with POs took place between October 2014 and April 2015, with three follow-up interviews taking place in May and June 2015. My interest in the work of professional organizers has grown out of a project that examines the emergence of Hoarding Disorder as a mental illness, public health hazard, and media spectacle during the past fifteen years. For this project, a key site of participant observation from 2013 to the present has been the Toronto Hoarding Coalition, a working group that was created in 2011 to bring together social workers, therapists, first responders, legal service providers, eldercare/child protective services, members of the Society for the Prevention of Cruelty to Animals, law enforcement officials, and cleaning specialists to address local hoarding cases and provide a clearinghouse for information.

4. Marilyn Strathern (1988) makes a strong case for the absolute distinctiveness of Melanesian (dividual) versus Western forms (individual) of personhood, an argument that Edward LiPuma (1998, 56-57) has strongly challenged, insisting instead that "in all cultures . . . there exist both individual and dividual modalities or aspects of personshood" and that "the foregrounding . . . of individual and dividual aspects of personhood will vary across contexts . . w within a given culture." In LiPuma's view, it is the tension between the two aspects that is the most productive site of investigation.

5. My use of the terms objects and things throughout this piece follows the retooled articulation of Martin Heidegger's distinction that was elaborated by Bill Brown (2001, 5): "We look through objects (to see what they disclose about history, society, nature, or culture - above all what they disclose about us), but we only catch a glimpse of things. We look through objects because there are codes by which our interpretive attention makes them meaningful, because there is a discourse of objectivity that allows us to use them as facts. A thing, in contrast, can hardly function as a window. . . . You could imagine things . . . as what is excessive in objects, as what exceeds their mere materialization as objects or their mere utilization as objects - their force as a sensuous presence." In this distinction, all things are objects, but not all objects are things. My usage also reflects the language used by POs and service providers, who most often refer to their client's material possessions as "their things" (when the items are somewhat individuated) and "their stuff" (when the items are being considered as a group).

6. In his introduction to The Social Life of Things, Arjun Appadurai $(1986,5)$ shook material objects from the tree of anthropological convention by challenging the discipline's "tendency to excessively sociologize transactions in things." Insisting that things have social lives and even biographies (see Kopytoff 1986), he incited anthropologists to follow them as they enter and exit distinct regimes of value and are swept up in alternating processes of commoditization, singularization, and care. Around the same time, an approach dubbed material culture studies emerged out of the University College London. Rooted in Hegelian dialectics, this group was less interested in tracing the social 
lives of objects than in interrogating how "things create people as much as people make them" (Tilley 1999, 76; cf. Miller 1987).

7. Bruno Latour $(1992,232)$ describes the automatic seatbelt safety feature in his car that renders impossible his ability to drive without buckling up as a telling example of our "delegat[ing] to nonhumans . . . values, duties, and ethics. It is because of this morality that we, humans, behave so ethically, no matter how weak and wicked we feel we are."

8. Carl Knappett and Lambros Malafouris's (2008) strong position in their attribution of agency to things has not gone uncontested, however. Tim Ingold (2007b, 1), for one, has insisted that this line of thinking obscures more than it clarifies: "Things are active not because they are imbued with agency but because of the ways in which they are caught up in these currents of the lifeworld." Ingold (2007a) instead looks to the ways that people, animals, and things are always already enmeshed and entangled with each other, and within themselves.

9. Here I follow the astute argument put forth by Ian Hacking $(1998,12)$ in his answer to the question of whether (or not) Multiple Personality Disorder is a "real" disorder: a "presupposition that we should reject," he writes, is "that there is an important contrast between being a real disorder and being a product of social circumstances."

10. This technique shares common elements with - but also inverts - the Kondo or KonMari method, a novel tidying method that has become spectacularly popular in North America during the past year. Based on the Japanese professional home organizer Marie Kondo's (2014) best-selling book The Life-Changing Magic of Tidying Up: The Japanese Art of Decluttering and Organizing, the key to this method is to contemplate each possession while asking yourself, "Does this item spark joy for me?" If it does, Kondo says, you must treasure the thing by treating it gently and kindly, by folding or arranging it with care, and by giving it a comfortable place to rest when not in use. If it does not, you must thank the object for its dedicated service and then let it go.

11. Boundary work can be dangerous. Fran, for example, told a cautionary tale about a PO who ran into problems and found herself in a similar situation to that of her clients: "Somebody I worked with . . . found herself creating a cocoon in her home office. She's an organizer. She said she just suddenly . . . was piling stuff in there. She said, 'I was piling it around me. I was doing the whole thing. I was trying to forget myself ..... And hearing her say that too, I mean, it's all too true that we end up having empathy."

\section{REFERENCES}

Abraham, Karl

1997 "Contributions to the Theory of the Anal Character." In Essential Papers on Obsessive-Compulsive Disorders, edited by Dan J. Stein and Michael H. Stone, 7390. New York: New York University Press. Originally published in 1921.

American Psychiatric Association

2013 Diagnostic and Statistical Manual of Mental Disorders. 5th edition. Washington, DC: American Psychiatric Publishing.

Appadurai, Arjun, ed.

1986 The Social Life of Things: Commodities in Cultural Perspective. Cambridge: Cambridge University Press.

Bennett, Jane

2004 “The Force of Things: Steps Toward an Ecology of Matter." Political Theory 32, no. 3: 347-72. http://dx.doi.org/10.1177/0090591703260853.

2010 Vibrant Matter: A Political Ecology of Things. Durham, N.C.: Duke University Press.

2012 "Powers of the Hoard: Further Notes on Material Agency." In Animal, Vegetable, Mineral: Ethics and Objects, edited by Jeffrey Cohen, 237-69. Washington, DC: Oliphaunt. 
Boero, Natalie

2007 “All the News That's Fat to Print: The American 'Obesity Epidemic' and the Media.” Qualitative Sociology 30, no. 1: 41-60. http://dx.doi.org/10.1007/ s11133-006-9010-4.

Bourdieu, Pierre

1977 Outline of a Theory of Practice. Translated by Richard Nice. New York: Cambridge University Press.

1984 Distinction: A Social Critique of the Judgment of Taste. Translated by Richard Nice. Cambridge, Mass.: Harvard University Press.

Brown, Bill

2001 “Thing Theory.” Critical Inquiry 28, no. 1: 1-22. http://www.jstor.org/stable/ 1344258 .

Campos, Paul, Abigail Saguy, Paul Ernsberger, Eric Oliver, and Glenn Gaesser

2006 "The Epidemiology of Overweight and Obesity: Public Health Crisis or Moral Panic?” International Journal of Epidemiology 35, no. 1: 55-60. http: / / dx.doi.org/ 10.1093/ije/dyi254.

Clarke, David A. G., and Jamie Mcphie

2014 "Becoming Animate in Education: Immanent Materiality and Outdoor Learning for Sustainability." Journal of Adventure Education and Outdoor Learning 14, no. 3: 198-216. http://dx.doi.org/10.1080/14729679.2014.919866.

Coole, Diane, and Samantha Frost, eds.

2010 New Materialisms: Ontology, Agency, and Politics. Durham, N.C.: Duke University Press.

Cvetkovich, Ann

2012 Depression: A Public Feeling. Durham, N.C.: Duke University Press.

Cwerner, Saulo B., and Alan Metcalfe

2003 "Storage and Clutter: Discourses and Practices of Order in the Domestic World." Journal of Design History 16, no. 3: 229-39. http://dx.doi.org/10.1093/jdh/ 16.3.229.

Denegri-Knott, Janice, and Elizabeth Parsons

2014 “Disordering Things.” Journal of Consumer Behaviour 13, no. 2: 89-98. http:// dx.doi.org/10.1002/cb. 1473.

Douglas, Mary

1966 Purity and Danger: An Analysis of Concepts of Pollution and Taboo. London: Routledge/Kegan Paul.

Frazer, James George

1906 The Golden Bough. The Magic Art and the Evolution of Kings, Part 1, Volume 1. London: Macmillan.

Freud, Sigmund

1959 "Character and Anal Erotism." In Standard Edition of the Complete Psychological Works of Sigmund Freud, Volume IX, edited and translated by James Strachey, 167-75. London: Hogarth. Originally published in 1908.

Frost, Randy O. and Gail Steketee

2010 Stuff: Compulsive Hoarding and the Meaning of Things. New York: Houghton Mifflin.

Frost, Randy, Gail Steketee, and David F. Tolin

2011 "Comorbidity in Hoarding Disorder." Depression and Anxiety 28, no. 10: 876-84.

Gell, Alfred http: / /dx.doi.org/10.1002/da.20861.

1998 Art and Agency: An Anthropological Theory. New York: Oxford University Press.

Gibson, Amanda K., Jessica Rasmussen, Gail Steketee, Randy Frost, and David Tolin

2010 "Ethical Considerations in the Treatment of Compulsive Hoarding." Cognitive and Behavioral Practice 17, no. 4: 426-38. http://dx.doi.org/10.1016/ j.cbpra.2009.06.008. 
Greenhalgh, Susan

2012 "Weighty Subjects: The Biopolitics of the U.S. War on Fat." American Ethnologist 39, no. 3: 471-87. http://dx.doi.org/10.1111/j.1548-1425.2012.01375.x.

Hacking, Ian

1998 Mad Travelers: Reflections on the Reality of Transient Mental Illnesses. Charlottesville: University of Virginia Press.

Halse, Christine

2009 "Bio-Citizenship: Virtue Discourses and the Birth of the Bio-Citizen." In Biopolitics and the "Obesity Epidemic": Governing Bodies, edited by Jan Wright and Haraway, Donna

Valerie Harwood, 45-59. New York: Routledge.

2003 The Companion Species Manifesto: Dogs, People, and Significant Otherness. Chicago: Prickly Paradigm.

Hodder, Ian

2012 Entangled: An Archaeology of the Relationships between Humans and Things. Malden, Mass.: Wiley-Blackwell.

Ingold, Tim

2007a Lines: A Brief History. New York: Routledge.

2007b "Materials against Materiality." Archaeological Dialogues 14, no. 1: 1-16. http:// dx.doi.org/10.1017/S1380203807002127.

2011 Being Alive: Essays on Movement, Knowledge, and Description. New York: Routledge. Jones, Ernest

1950 “Anal-Erotic Character Traits.” In Papers on Psychoanalysis, 5th edition, 413-37.

Kirmayer, Laurence J.

London: Baillière, Tindall, and Cox. Originally published in 1918.

2002 "Psychopharmacology in a Globalizing World: The Use of Antidepressants in Japan.” Transcultural Psychiatry 39, no. 3: 295-322. http://dx.doi.org/10.1177/ 136346150203900302 .

Kleinman, Arthur

1988 The Illness Narratives: Suffering, Healing, and the Human Condition. New York: Basic Books.

Kondo, Marie

2014 The Life-Changing Magic of Tidying $U_{p}$ : The Japanese Art of Decluttering and Kopytoff, Igor Organizing. New York: Ten Speed.

1986 “The Cultural Biography of Things: Commoditization as Process." In The Social Life of Things: Commodities in Cultural Perspective, edited by Arjun Appadurai, 64 91. New York: Cambridge University Press.

Knappett, Carl, and Lambros Malafouris, eds.

2008 Material Agency: Towards a Non-Anthropocentric Approach. New York: Springer.

Latour, Bruno

1987 Science in Action: How to Follow Scientists and Engineers through Society. Cambridge, Mass.: Harvard University Press.

1992 "Where Are the Missing Masses? The Sociology of a Few Mundane Artifacts." In Shaping Technology/Building Society, edited by John Law and Wiebe E. Bijker, 225-64. Cambridge, Mass.: MIT Press.

Law, John

1992 "Notes on the Theory of the Actor-Network: Ordering, Strategy, and Heterogeneity." Systems Practice 5, no. 4: 379-93. http://dx.doi.org/10.1007/ BF01059830.

1994 Organizing Modernity: Social Ordering and Social Theory. Cambridge, Mass.: Blackwell.

Lepselter, Susan

2011 "The Disorder of Things: Hoarding Narratives in Popular Media." Anthropological Quarterly 84, no. 4: 919-47. http://dx.doi.org/10.1353/anq.2011.0053. 
LiPuma, Edward

1998 "Modernity and Forms of Personhood in Melanesia." In Bodies and Persons: Comparative Perspectives from Africa and Melanesia, edited by Michael Lambek and Andrew Strathern, 53-79. New York: Cambridge University Press.

Littlewood, Roland

2002 Pathologies of the West: An Anthropology of Mental Illness in Europe and America. Ithaca, Lovell, Anne M. N.Y.: Cornell University Press.

2007 "Hoarders and Scrappers: Madness and the Social Person in the Interstices of the City." In Subjectivity: Ethnographic Investigations, edited by João Biehl, Byron

Martin, Emily Good, and Arthur Kleinman, 215-39. Berkeley: University of California Press.

2007 Bipolar Expeditions: Mania and Depression in American Culture. Princeton, N.J.:

Mataix-Cols, David Princeton University Press.

2014 “Hoarding Disorder." New England Journal of Medicine 370: 2023-30. http:// dx.doi.org/10.1056/NEJMcp1313051.

Mataix-Cols, David, Randy O. Frost, Alberto Pertusa, Lee Anna Clark, Sanjaya Saxena,

James F. Leckman, Dan J. Stein, Hisato Matsunaga, and Sabine Wilhelm

2010 "Hoarding Disorder: A New Diagnosis for DSM-V?" Depression and Anxiety 27, no. 6: 556-72. http://dx.doi.org/10.1002/da.20693.

Mauss, Marcel

1972 A General Theory of Magic. Translated by Robert Brain. London: Routledge/Kegan Paul.

Millburn, Joshua Fields, and Ryan Nicodemus

2011 Minimalism: Live a Meaningful Life. Columbia, Mo.: Asymmetrical.

Miller, Daniel

1987 Material Culture and Mass Consumption. Oxford: Blackwell.

Newell, Sasha

2014 "The Matter of the Unfetish: Hoarding and the Spirit of Possessions." HAU:

Journal of Ethnographic Theory 4, no. 3: 185-213. http://dx.doi.org/10.14318/ hau4.3.013.

Poe, Andrew

2011 "Review Essay: Things-Beyond Objects." Journal of French and Francophone Philosophy 19, no. 1: 153-64. http://dx.doi.org/10.5195/jffp.2011.484.

Steketee, Gail, and Randy Frost

2003 “Compulsive Hoarding: Current Status of the Research.” Clinical Psychology Review 23, no. 7: 905-27. http://dx.doi.org/10.1016/j.cpr.2003.08.002.

Strathern, Marilyn

1988 The Gender of the Gift: Problems with Women and Problems with Society in Melanesia.

Tilley, Christopher

Berkeley: University of California Press.

1999 Metaphor and Material Culture. Oxford: Blackwell.

Veblen, Thorstein

1899 The Theory of the Leisure Class: An Economic Study of Institutions. New York: Macmillan. 